\title{
Safety and danger of biologic treatments in psoriasis in context of cutaneous T-cell lymphoma (CTCL)
}

\author{
Karol Kołkowski¹, Małgorzata Sokołowska-Wojdyło²
}

1Dermatological Students Scientific Association, Department of Dermatology, Venerology and Allergology, Faculty of Medicine, Medical University of Gdansk, Gdansk, Poland

${ }^{2}$ Department of Dermatology, Venereology and Allergology, Faculty of Medicine, Medical University of Gdansk, Gdansk, Poland

Adv Dermatol Allergol 2021; XXXVIII (6): 953-960

DOI: https://doi.org/10.5114/ada.2021.107553

\begin{abstract}
Microenvironment has a significant impact on the pathogenesis of cutaneous T-cell lymphoma (CTCL), especially in the context of new emerging biologic therapies. Our aim was to review the literature on interleukins $12,17,23$ and tumour necrosis factor- $\alpha$ in mycosis fungoides in order to clarify the safety of using biologics in the treatment of psoriasis. Our analysis suggests that these drugs may have an impact on the progression of CTCL. Concluding, in case of uncertain psoriatic lesions, a biopsy followed by pathologic examination should exclude the possibility of co-existence of a primary cutaneous lymphoma before administration of therapies affecting cytokine profiles.
\end{abstract}

Key words: cutaneous T-cell lymphoma, mycosis fungoides, biologic treatment, psoriasis, interleukin-12, interleukin-17, tumour necrosis factor- $\alpha$.

\section{Introduction}

Mycosis fungoides (MF), a rare lymphoproliferative disorder characterized by accumulation of malignant Tcells in the skin, is the most common cutaneous T-cell lymphoma (CTCL) [1]. Pathophysiological mechanisms causing the progression of this disease have not been fully understood. A possible impact of tumour microenvironment on the development of the disease has been shown in some recent studies suggesting the impact of interleukin-17 (IL-17) in that matter [2]. A variety of therapies affecting cytokine profiles have been introduced, including tumour necrosis factor $\alpha$ (TNF- $\alpha$ )-inhibitors and TNF- $\alpha$-receptor inhibitors (e.g. adalimumab, etanercept, infliximab), IL-17 and its receptor pathway blockers (bimekizumab, brodalumab, ixekizumab, secukinumab) and IL-12 and/or IL-23 pathway blockers (e.g. guselkumab, ixekizumab, risankizumab, secukinumab, tildrakizumab, and ustekinumab). They have been used more often in the clinical practice for the last decade.

Our aim in this review is to elucidate the role of IL-12, IL-17, IL-23 and TNF- $\alpha$ in MF, which sheds the light on the safety of new biologic treatments in psoriasis in context of CTCL.

\section{Involvement of IL-17 in MF}

The IL-17 family currently consists of six cytokines (named IL-17A to IL-17F) and five receptors (IL-17RA to IL-17RE) [3]. IL-17A, IL-17C and IL-17F are identified as proinflammatory, whereas IL-17E, also termed IL-25, is considered as anti-inflammatory [4]. IL-17A and IL-17F have $50 \%$ homology, therefore IL-17F signalling is 10-30-fold weaker [5]. IL-17A/17F heterodimer may also be secreted, and its signalling strength is intermediate [5].

IL-17A and IL-17F are secreted by many cells including Th17 cells, mast cells, macrophages, neutrophils and CD8+ lymphocytes [6]. The IL-17 cytokines are crucial in the answer against extracellular bacteria and fungi. When not strictly controlled, they can also contribute to development of pathogenic response causing autoimmune disorders such as psoriasis [7]. Possible involvement of IL-17 in the pathogenesis of MF has been reported by researchers [8-18].

In 2004 Cirée et al. were the first to reveal that tumour cells may express IL-17. The cells derived from patients diagnosed with MF or Sezary syndrome (SS) expressed IL-17 mRNA and secreted this cytokine in vitro [9]. Since then, several studies have reported conflicting

Address for correspondence: Karol Kołkowski, Dermatological Students Scientific Association, Department of Dermatology, Venerology and Allergology, Faculty of Medicine, Medical University of Gdansk, 17 Smoluchowskiego St, 80-214 Gdansk, Poland, phone: +48 662296 221, e-mail: karolkolkowski@gumed.edu.pl Received: 9.03.2021, accepted: 25.03.2021. 
results. We have found five studies, which have shown the elevated levels of IL-17 in biopsies from MF skin lesions [8, 11-13, 18]. IL-17F cytokine is known to induce gene expression of antimicrobial peptides (AMPs), other proinflammatory cytokines and matrix metalloproteinases (MMPs) [19] by activating numerous pathways

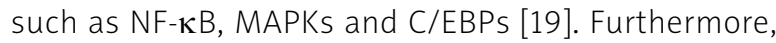
IL-17F expression was associated with progressive CTCL [13]. Studies have also revealed that malignant lymphocytes in MF may present a Th-17 phenotype [11] which has been shown to express not only IL-17, but also IL-21, IL-22 and CCL20 [20, 21]. Two other studies have shown the results with normal levels of IL-17 in MF $[10,14]$. One of them is suggesting that IL-22 rather than IL-17 is crucial in establishing the tumour microenvironment [10].

It is well known that activation of STAT3/JAK3 pathway plays a significant role in MF pathogenesis [11]. Krejsgaard et al. have found that malignant T-cells in CTCL not only can express IL-17, but also that expression is promoted by the JAK3/STAT3 pathway [11]. The-IL-17 pathway is important in innate defence mechanisms, promoting secretion of anti-microbial peptides (AMPs) or neutrophil-recruiting cytokines, thereby improving response against extracellular pathogens, e.g. Staphylococcus aureus [22]. Recently, it has been proven that T-cell receptor (TCR) engagement is necessary for malignant transformation in MF and that the progression of the disease is dependent also on microbiota [23]. The aetiology of MF is still elusive, nevertheless some bacterial agents are suspected to play an etiologic role. S. aureus has been one of them - reported to colonize $44-76 \%$ of CTCL patients [24-26] and to be the most common infection in CTCL [25]. Staphylococcal enterotoxin A (SEA) has been shown to stimulate activation of STAT3 and upregulate IL-17 production in primary patient-derived malignant and non-malignant T cells [16]. Researchers demonstrated the interesting cross-talk between malignant T-cells expressing SEA-nonresponsive TCR variable region $\beta$ chain and non-malignant T-cell with SEA-responsive TCR, what may suggest that SEA-producing bacteria can promote the STAT3/JAK3 oncogenic pathway [16]. Furthermore, this may be the possible mechanism of the MF progression.

Despite those possible mechanisms and the elevated levels of IL-17 observed in MF patients [8, 11-13, 18], secretion of anti-microbial peptides is significantly lower in CTCL patients than in psoriatic skin. It may resemble what is seen in atopic dermatitis (AD) [14, 27], thereby suggesting the dysfunction in the induction of gene expression of antimicrobial peptides by IL-17, which is its role in healthy skin. Furthermore, studies seem to suggest the Th-2 cytokines to be the main players in advanced stages of MF and SS [28-30]. One study concerning IL-17E, called IL-25 here, showed that IL-25 levels are elevated in MF lesions and in sera of advance-stage patients, which also correlates with lactate dehydroge- nase levels [18] known to reflect the CTCL activity [31]. What they concluded using MyLa cell lines (MF cell lines) was that IL-25 is secreted by epidermal keratinocytes in MF and may directly induce IL-13 secretion by tumour cells, which may contribute to formation of Th-2 microenvironment [18]. This mechanism seems to be relevant in the pathogenesis of MF and SS and may be clinically important since Geskin et al. established IL-13 to be an autocrine factor of CTCL, blocking of which may be the potential therapeutic target for clinical interventions [32].

\section{Possible cancerogenic role of IL-17 in MF}

Many studies have shown the link between IL-17 mediated answer and cancerogenesis, e.g. in colorectal cancer [33-37], lung cancer [38] and in squamous cell carcinoma (SCC) $[39,40]$.

A role of IL-17 in CTCL carcinogenesis has been still elusive to the best of our knowledge. Nevertheless, the pro-angiogenic role of IL-17 has been postulated in a few studies, therefore suggesting an indirect pro-carcinogenetic role. Along with the worsening survival rates as the stages of CTCL progress [1], some studies show that in the plaque and tumour stages, the value of the mean microvessel area is significantly higher [41, 42]. The promotion of angiogenesis is contributed to many factors and vascular endothelial growth factor (VEGF) has been one of them, a potent angiogenic protein, which is strongly induced by hypoxia [43]. The resistance of lymphomas, colorectal and lung cancer tumour models to treatment with anti-VEGF drugs, was promoted by Th17 subset cells [44]. VEGF has been present in CTCL lesions [45, 46] and its production is associated with constitutive activity of Janus kinase 3 (Jak3) and the c-Jun N-terminal kinases (JNKS) [45]. Moreover, Lauenborg et al. have shown that IL-17F secreted by malignant T-cell of MyLa2059 cell lines was able to trigger endothelial tube formation, thereby proving stimulation of angiogenesis by IL-17F [47]. Accordingly, when applying anti-cancer treatment, e.g. CHOP (cyclophosphamide, hydroxydaunorubicin, oncovin and prednisone) chemotherapy, IL-17 pathways may be indirectly promoted shifting to Th17 phenotype [17]. Similarly, promotion of Th17 pro-inflammatory cytokines has been noticed in colorectal carcinoma after administration of tamoxifen [37]. Moreover, IL-17RA blocking may be used to potentiate the response to such treatment [37]. Nevertheless, chemotherapy is not recommended as a first-line treatment for CTCL [48]. Mono- and polychemotherapy show elevated risks of death, no chemotherapy regimen has been shown to improve patients survival rates and remissions are significantly short [48]. In summary, IL-17 may have an impact on the promotion of carcinogenesis in MF and a possible aggravating role during chemotherapy. Despite some evidence of positive effects of blocking Th17 pathway during chemotherapy, for now, it is rather not a possible treatment in CTCL [48]. 


\section{Role of IL-12/IL-23 in MF}

Considering the impact of new biologic therapies on $\mathrm{CTCL}$, it is important to mention the role of IL-12 and IL-23. Both cytokines, which share the same common subunit p40, are known to have pro-inflammatory effects [49]. Interestingly, despite having many similar functions, pre-Th-1 cells differentiate into Th-1 lymphocytes in the presence of IL-12, when IL-23 is present, they rather show Th-17 profile [50]. Though it is important to remember that Th-17 cells are easily interconvertible and they can be turned into Th-1 or Th-2 cells, when a suitable microenvironment occurs, but not vice versa [51]. Therefore recombinant IL-12, strongly inducing Th-1 microenvironment and with its ability to suppress Th-2 cytokines in SS, was considered as one of the emerging therapies for MF [52-54]. The main rationale for use of this cytokine in CTCL treatment was to enhance cell-mediated cytotoxicity and to restore interferon $\gamma($ IFN- $\gamma$ ) production [55], which expression has been shown to gradually decrease in the course of lymphoma progression [56]. IFN- $\gamma$ has been used in MF treatment [57]. Phase II open-label study of recombinant human IL-12 in SS, which was administered in two subcutaneous injections per week in doses ranging from $100 \mathrm{ng} / \mathrm{kg}$ escalating up to $300 \mathrm{ng} / \mathrm{kg}$, has shown some antitumor activity [58]. Another aspect is that IL-12 may be used as an early MF marker. Immunohistochemical staining of IL-12p35 has been shown to be useful as the diagnostic tool in patch-stage MF [59] along with exhibition of Th-1 dominant microenvironment in early stages of the disease [30]. The literature on IL-23 in MF is scarce. Due to the fact that IL-23 may induce pre-Th-1 cells to convert to Th-17, there is a possibility that this cytokine activates the secretion of IL-17A and IL$17 \mathrm{~F}$, thereby promoting the possible pathogenic effects of IL-17A and IL-17F. Doherty et al. have shown that there was an increased expression of IL-23 in keratinocytes and in dermal lymphocytes in all stages of MF, and that atypical lymphocytes infiltrating the tumour in IVB stage patients may demonstrate a weaker staining of IL-23 [60]. This finding shows that IL-23 may play a role in the pathogenesis of MF/SS, but further research is necessary.

\section{Role of TNF- $\alpha$ in MF}

TNF- $\alpha$, the hallmark of pro-inflammatory cytokines, has also been shown to have an impact on MF. Studies seem to be consistent with the fact that TNF- $\alpha$ levels are elevated in the MF skin lesions [56, 61, 62]. Moreover, an increase in the cytokine concentration concomitant with the progression of the disease has been noticed [62] but not in all of cases [56]. What is also worth mentioning, serum concentrations of TNF- $\alpha$ in patients during treatment of CTCLs with extracorporeal photophoresis $(E C P)$, have significantly increased from baseline during 6 months' therapy, but no correlation with clinical response has been found [63]. Genetic studies suggest that patch-stage of MF is not determined by TNF- $\alpha$ genotype polymorphism [64]; however, Tracey et al. have found an association between tumorigenesis in MF and alteration in TNF receptor signalling [65]. They show the possibility of activating antiapoptotic pathways through first and second TNF receptors (TNFR1 and TNFR2) caused by deregulation of multiple genes, leading the lymphoma cells to avoid apoptosis, predominantly because of NF- $\mathrm{KB}$ upregulation [65]. Strong expression of these transcription factors may be one of the characteristic features presented by some MF cell lines [66]. Other researchers have shown that constitutive activation of NF- $\kappa \mathrm{B}$, pathway promoted by TNF- $\alpha$, can cause the resistance to apoptosis in lymphoma HuT-78 cells [67]. TNF- $\alpha$, alongside with IFN- $\gamma$, has been suspected to be one of the factors causing the epidermotropism in CTCL by inducing InterferonInducible Protein (IP-10) [56, 61]. Some of these latter reports were the basis to assess the treatment of a relapsed CTCL with soluble TNF receptor, etanercept [68]. Before the administration of the biologic drug, patients were heavily pretreated (median number of prior regimens was seven) [68]. This therapy was not effective in case of patients in the advanced stage of the disease: all of them did not respond and progressed [68]. Only two patients in the early stage of CTCL (both in IB), had some benefit from the therapy, one with partial response and the other with minor response [68], nevertheless this group is too small to make any reasonable conclusions.

\section{MF, psoriasis and biological treatment implications}

A significant pathogenetic role of IL-23, IL-17 and TNF$\alpha$ in psoriasis is widely accepted and has important clinical implications in biological treatments of the disease. Anti-TNF- $\alpha$ drugs such as infliximab [69] and agents blocking IL-23, IL-17 pathway e.g. ustekinumab [70], ixekizumab [71] and secukinumab [72, 73] are more commonly used to treat chronic plaque psoriasis, often with superior therapeutic effects and increased quality of life $[74,75]$. However, many studies have reported an increased risk of CTCL in patients with psoriasis both in Caucasian and Asian populations [76-78], especially in severe psoriasis [76, 78]. A major review on that topic also concluded that an association between MF and psoriasis is plausible, but prevalence and incidence have not been found yet [79]. Therefore, a question about the effect of these biologic therapies on the course of MF is raised. We believe that the most important issues here have been similar to those considered by Dequidt et al. [80]. First, if the biologic treatments in psoriasis may induce MF and second, in case of an overlap or misdiagnosis between those two diseases, if lymphoma may progress after administration of biologic drugs. Solely basing on the above assumptions, blocking IL-17RA (brodalumab), IL-17A (secukinumab, ixekizumab) and IL-17A-F (bi- 


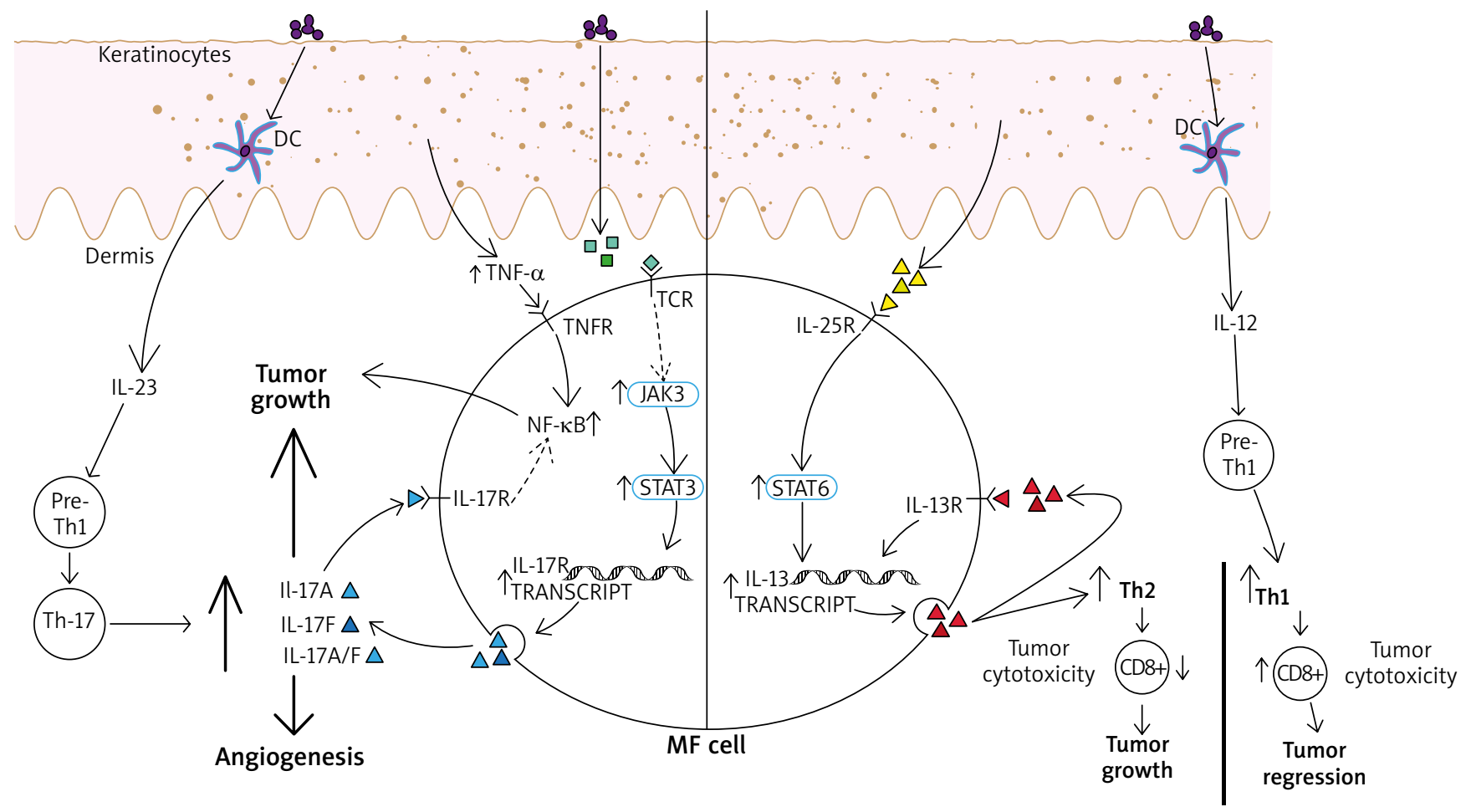
8\& Extracellular pathogens, e.g. S. aureus
$\Delta \Delta$ Interleukin-17
믐 Staphylococcal Enterotoxin A
Lymphocyte
$\Delta \Delta$ Interleukin-13
$\Delta_{\Delta}^{\Delta}$ Interleukin-25
b Dendritic cell

Figure 1. The contribution of interleukins (IL) 12, 17, 23 and tumour necrosis factor $\alpha$ (TNF- $\alpha$ ) to the tumour microenvironment in mycosis fungoides (MF). IL-12 has been indirectly restoring the cytotoxic mediated CD8(+) answer and promoting tumour regression by stimulating the differentiation of pre-T-helper 1 lymphocytes. IL-23 can stimulate pre-T-helper 1 lymphocytes, followed by creating T-helper 17 cells subset and increased secretion of IL-17 proinflammatory cytokines. MF cell is also able to secrete IL-17A, IL-17F and IL-17A/IL-17F heterodimers. It is reinforced by upregulated JAK3/STAT3 pathway, which has been shown to be promoted by activated T-cell receptor (TCR), which is necessary for malignant transformation in MF to occur. One of the possible ways of activating TCR is related to Staphylococcal enterotoxin A. NF-kB upregulation, with its anti-apoptotic effect on lymphoma cells, seems to be important and relevant in the pathogenesis of CTCL. It has been promoted by TNF- $\alpha$ as well as proinflammatory IL-17 cytokines. IL-25 (IL-17E) is promoting STAT6 pathway. Those interactions result in increased IL-13 secretion (also in autocrine manner). Especially in the advanced stage of the disease it contributes to forming Th-2 cytokine profile, what results in decreased cytotoxic immunosurveillance and tumour growth

mekizumab) may be beneficial in stopping progression of MF as we have shown the possible role of proinflammatory IL-17 cytokines. IL-17A and IL-17F may be included in progression of the disease by promoting the JAK3/STAT3 oncogenic pathway and by stimulation of angiogenesis. Furthermore, the anti-inflammatory cytokine, IL-17E, may contribute to creating a Th-2 dependent tumour microenvironment by inducing IL-13 secretion and brodalumab should be able to block this interaction. On the other hand, ustekinumab (blocker of p40 common subunit) and TNF- $\alpha$ inhibitors should not be recommended in the treatment of psoriasis if there is any risk of an overlap with CTCL as they are known to inhibit Th-1 microenvironment. Moreover, as it was shown, etanercept did not appear to be an effective drug in the treatment of CTCL, possibly causing the progression in some patients. Considering all the theoretical background, we have to focus on what researchers have found and published. Studies on the impact of anti-TNF- $\alpha$ drugs on the course of CTCL are much more abundant in contrast to the literature on other biologic therapies. We have identified 7 patients described in clinical case studies [81-85] and 90 cases from retrospective studies [80, 86-89] reporting CTCL after TNF- $\alpha$-inhibitor treatment. Eighty-two out of these 97 patients presented with CTCLs, 66 of which were classified as MF and 5 as SS [80-89]. Dequidt et al. reported that in each of the 5 cases of large cell transformation in MF, the diagnosis of psoriasis was the reason to treat 
with biologic drugs and after discontinuing anti-TNF- $\alpha$, the evolution of the lymphoma was aggressive [80]. Another study has revealed that the majority of MF were misdiagnosed, predominantly as psoriasis, and biologic drugs made the lymphoma fully apparent [87]. During follow-up, 7 patients died because of the CTCL that appeared after the anti-TNF- $\alpha$ administration, all of them in the advanced stage of the disease $[86,88,89]$. On the other hand, most cases of MF have appeared indolent after anti-TNF- $\alpha$ drugs were discontinued, in some cases the topical treatment led to partial or complete response $[80,89]$. Moreover, majority of the patients had either a stable disease or a complete response after receiving a stage-suited therapy [80-89]. These results seem to be consistent with our previous considerations.

What may be surprising in terms of our IL-17 findings is what studies show. Most of the MF patients may progress after receiving IL-17A, IL-17RA or IL-12/23 inhibitors [80-82, 89, 90]. In fact, some case report has shown significant clinical improvements after discontinuing of these drugs [81]. Nevertheless, the biggest study on that matter has shown that in 8 of 11 cases, a worsening of the disease was noticed and in the short follow-up of thirteen months 5 patients died, 4 of MF and one of stroke [89]. In contrast to these reports, our assumptions highlighted the possible aggravating role of IL-17 in MF, therefore blocking it would be beneficial. The explanation to these conflicting data may be the aspect of Th17/Treg imbalance leading to immunosuppression [90] and other, not yet known mechanisms. Admittedly, despite the fact that the literature is scarce on the effects of these newest biologic therapies on MF, it seems to be ethically questionable to make further intentional research elucidating these aspects. Also, many authors emphasized what may be done in order to minimize the risk of a lymphoma progression after receiving biological drugs. The most important conclusion is to carefully examine patients and in case of any oncological suspicion, take biopsies in order to exclude a potential misdiagnosis $[80,82-86,89,90]$.

The main limitation of the study in the aspect of biologic therapies is based on the retrospective studies and case reports. The disturbing role of some other medicaments, like cyclosporine, also cannot be excluded, since most patients with psoriasis have undergone at least one non-biological systemic therapy before receiving biologic drugs.

\section{Conclusions}

Interleukin-17 is detectable in MF lesions, sometimes with the elevated level, but it does not seem to be the main player of MF. We show it not to be as important in the pathogenesis of CTCLs as it is in the pathogenesis of psoriasis, nevertheless using IL-17 or IL-17RA blockers (bimekizumab, brodalumab, ixekizumab, secukinumab) may cause a progression of MF in case of an overlap or a misdiagnosis of the mentioned autoimmune disease. Based on the literature, we have also described the beneficial effects of IL-12 on MF, therefore the agents blocking both IL-12/IL-23 pathway (ustekinumab) should be avoided in patients, who have a suspicion or a diagnosed MF. Lastly, the overall contribution of TNF- $\alpha$ to creating cell mediated cytotoxic Th1 microenvironment seems to outweigh the negative effects of TNF-a on the lymphoma, which was reported. TNF- $\alpha$-inhibitors and TNF- $\alpha$-receptor inhibitors (e.g. adalimumab, etanercept, infliximab) should not be used if CTCL cannot be ruled out. Before introducing the biological treatment, in case of advanced to severe psoriasis, we recommend performing a biopsy from the skin lesion followed up by a close pathological examination to exclude the possibility of MF misdiagnosis. We believe that further research is necessary to clarify the role of IL-17, IL-23 and TNF- $\alpha$ in MF and new immunosuppressive drugs should be used carefully in order not to aggravate the plausible lymphoma.

\section{Conflict of interest}

The authors declare no conflict of interest.

\section{References}

1. Olsen E, Vonderheid E, Pimpinelli N, et al. Revisions to the staging and classification of mycosis fungoides and Sézary syndrome: a proposal of the International Society for $\mathrm{Cu}$ taneous Lymphomas (ISCL) and the cutaneous lymphoma task force of the European Organization of Research and Treatment of Ca. Blood 2007; 110: 1713-22.

2. Gonzalez BR, Zain J, Rosen ST, et al. Tumor microenvironment in mycosis fungoides and Sézary syndrome. Curr Opin Oncol 2016; 28: 88-96.

3. Gaffen SL. Life before seventeen: cloning of the IL-17 receptor. J Immunol 2011; 187: 4389-91.

4. Brockmann L, Giannou AD, Gagliani N, et al. Regulation of Th17 cells and associated cytokines in wound healing, tissue regeneration, and carcinogenesis. Int J Mol Sci 2017; 18: 1033.

5. Gaffen SL. Structure and signalling in the IL-17 receptor family. Nat Rev Immunol 2009; 9: 556-67.

6. Monin L, Gaffen SL. Interleukin 17 family cytokines: signaling mechanisms, biological activities, and therapeutic implications. Cold Spring Harb Perspect Biol 2018; 10: a028522.

7. Speeckaert R, Lambert J, Grine L, et al. The many faces of interleukin-17 in inflammatory skin diseases. Br J Dermatol 2016; 175: 892-901.

8. Chong BF, Wilson AJ, Gibson HM, et al. Immune function abnormalities in peripheral blood mononuclear cell cytokine expression differentiates stages of cutaneous T-cell lymphoma/mycosis fungoides. Clin Cancer Res 2008; 14: 646-53.

9. Cirée A, Michel L, Camilleri-Bröet S, et al. Expression and activity of IL-17 in cutaneous T-cell lymphomas (mycosis fungoides and Sezary syndrome). Int I Cancer 2004; 112: 113-20.

10. Miyagaki T, Sugaya M, Suga H, et al. IL-22, but not IL-17, dominant environment in cutaneous T-cell lymphoma. Clin Cancer Res 2011; 17: 7529-38. 
11. Krejsgaard T, Ralfkiaer U, Clasen-Linde E, et al. Malignant cutaneous T-cell lymphoma cells express IL-17 utilizing the Jak3/stat3 signaling pathway. J Invest Dermatol 2011; 131: 1331-8.

12. Fontao L, Brembilla NC, Masouyé I, et al. Interleukin-17 expression in neutrophils and Th17 cells in cutaneous T-cel lymphoma associated with neutrophilic infiltrate of the skin. Br J Dermatol 2012; 166: 687-9.

13. Krejsgaard T, Litvinov IV, Wang Y, et al. Elucidating the role of interleukin-17F in cutaneous T-cell lymphoma. Blood 2013; 122: 943-50.

14. Wolk K, Mitsui H, Witte K, et al. Deficient cutaneous antibacterial competence in cutaneous T-cell lymphomas: role of Th2-mediated biased Th17 function. Clin Cancer Res 2014 20: $5507-16$

15. Willerslev-Olsen A, Litvinov IV, Fredholm SM, et al. IL-15 and $\mathrm{IL}-17 \mathrm{~F}$ are differentially regulated and expressed in mycosis fungoides (MF). Cell Cycle 2014; 13: 1306-12.

16. Willerslev-Olsen A, Krejsgaard T, Lindahl LM, et al. Staphylococcal enterotoxin A (SEA) stimulates STAT3 activation and IL-17 expression in cutaneous T-cell lymphoma. Blood 2016; 127: 1287-96.

17. Wang B, Li K, Wang H, et al. Systemic chemotherapy promotes HIF-1 $\alpha$-mediated glycolysis and IL-17F pathways in cutaneous T-cell lymphoma. Exp Dermatol 2020; 29: 987-92.

18. Nakajima R, Miyagaki T, Hirakawa M, et al. Interleukin-25 is involved in cutaneous T-cell lymphoma progression by establishing a $\mathrm{T}$ helper 2-dominant microenvironment. $\mathrm{Br}$ J Dermatol 2018; 178: 1373-82.

19. Song X, Qian Y. The activation and regulation of IL-17 receptor mediated signaling. Cytokine 2013; 62: 175-82

20. Knochelmann HM, Dwyer CJ, Bailey SR, et al. When worlds collide: Th17 and Treg cells in cancer and autoimmunity. Cell Mol Immunol 2018; 15: 458-69.

21. Liang SC, Tan XY, Luxenberg DP, et al. Interleukin (IL)-22 and IL-17 are coexpressed by Th17 cells and cooperatively enhance expression of antimicrobial peptides. J Exp Med 2006; 203: 2271-9.

22. Bekeredjian-Ding I, Stein C, Uebele J. The innate immune response against Staphylococcus aureus. Curr Topics Microbio Immunol 2017; 409: 385-418.

23. Fanok MH, Sun A, Fogli LK, et al. Role of dysregulated cy tokine signaling and bacterial triggers in the pathogenesis of cutaneous T-cell lymphoma. J Invest Dermatol 2018; 138 1116-25.

24. Nguyen V, Huggins RH, Lertsburapa T, et al. Cutaneous T-cel lymphoma and Staphylococcus aureus colonization. J Am Acad Dermatol 2008; 59: 949-52.

25. Jackow CM, Cather JC, hearne V, et al. Association of erythrodermic cutaneous T-cell lymphoma, superantigen-positive Staphylococcus aureus, and oligoclonal T-cell receptor $V$ beta gene expansion. Blood 1997; 89: 32-40.

26. Talpur R, Bassett R, Duvic M. Prevalence and treatment of Staphylococcus aureus colonization in patients with mycosis fungoides and Sézary syndrome. Br J Dermatol 2008; 159: 105-12.

27. Suga H, Sugaya M, Miyagaki T, et al. Skin barrier dysfunction and low antimicrobial peptide expression in cutaneous T-cel lymphoma. Clin Cancer Res 2014; 20: 4339-48.

28. Vowels BR, Lessin SR, Cassin M, et al. Th2 cytokine mRNA expression in skin in cutaneous T-cell lymphoma. J Invest Dermatol 1994; 103: 669-73.
29. Vowels BR, Cassin M, Vonderheid EC, et al. Aberrant cytokine production by sezary syndrome patients: cytokine secretion pattern resembles murine Th2 cells. J Invest Dermatol 1992; 99: 90-4.

30. Saed G, Fivenson DP, Naidu Y, et al. Mycosis fungoides exhibits a Th1-type cell-mediated cytokine profile whereas Sezary syndrome expresses a Th2-type profile. J Invest Dermatol 1994; 103: 29-33.

31. Martí RM, Estrach T, Reverter JC, et al. Prognostic clinicopathologic factors in cutaneous T-cell lymphoma. Arch Dermatol 1991; 127: 1511-6.

32. Geskin LJ, Viragova S, Stolz DB, et al. Interleukin-13 is overexpressed in cutaneous T-cell lymphoma cells and regulates their proliferation. Blood 2015; 125: 2798-805.

33. Chung L, Thiele Orberg E, Geis AL, et al. Bacteroides fragilis toxin coordinates a pro-carcinogenic inflammatory cascade via targeting of colonic epithelial cells. Cell Host Microbe 2018; 23: 203-14.e5.

34. Wu S, Rhee KJ, Albesiano E, et al. A human colonic commensal promotes colon tumorigenesis via activation of $\mathrm{T}$ helper type 17 T cell responses. Nat Med 2009; 15: 1016-22.

35. Housseau F, Sears CL. Enterotoxigenic Bacteroides fragilis (ETBF)-mediated colitis in Min (Apc+/-) mice: a human commensal-based murine model of colon carcinogenesis. Cell Cycle 2010; 9: 3-5.

36. Zepp JA, Zhao J, Liu C, et al. IL-17A-induced PLET1 expression contributes to tissue repair and colon tumorigenesis. J Immunol 2017; 199: 3849-57.

37. Wang K, Kim MK, DiCaro G, et al. Interleukin-17 receptor a signaling in transformed enterocytes promotes early colorectal tumorigenesis. Immunity 2014; 41: 1052-63.

38. Jin C, Lagoudas GK, Zhao C, et al. Commensal microbiota promote lung cancer development via $\gamma \delta$ T cells. Cell 2019; 176: 998-1013.e16.

39. Wang L, Yi T, Kortylewski M, et al. IL-17 can promote tumor growth through an IL-6-Stat3 signaling pathway. J Exp Med 2009; 206: 1457-64.

40. Chen X, Cai G, Liu C, et al. IL-17R-EGFR axis links wound healing to tumorigenesis in Lrig1 + stem cells. J Exp Med 2019; 216: 195-214.

41. Mazur G, Woźniak Z, Wróbel T, et al. Increased angiogenesis in cutaneous T-cell lymphomas. Pathol Oncol Res 2004; 10: 34-6.

42. Vacca A, Moretti S, Ribatti D, et al. Progression of mycosis fungoides is associated with changes in angiogenesis and expression of the matrix metalloproteinases 2 and 9. Eur J Cancer 1997; 33: 1685-92.

43. Ferrara N. Vascular endothelial growth factor: basic science and clinical progress. Endocr Rev 2004; 25: 581-611.

44. Chung AS, Wu X, Zhuang G, et al. An interleukin-17-mediated paracrine network promotes tumor resistance to antiangiogenic therapy. Nat Med 2013; 19: 1114-23.

45. Krejsgaard T, Vetter-Kauczok CS, Woetmann A, et al. Jak3and JNK-dependent vascular endothelial growth factor expression in cutaneous T-cell lymphoma. Leukemia 2006; 20: 1759-66.

46. Hansen ER, Vejlsgaard GL, Lisby S, et al. Epidermal interleukin $1 \alpha$ functional activity and interleukin 8 immunoreactivity are increased in patients with cutaneous T-cell lymphoma. J Invest Dermatol 1991; 97: 818-23.

47. Lauenborg B, Litvinov IV, Zhou Y, et al. Malignant T cells activate endothelial cells via IL-17 F. Blood Cancer J 2017; 7: e586. 
48. Quaglino P, Maule M, Prince HM, et al. Global patterns of care in advanced stage mycosis fungoides/Sezary syndrome: a multicenter retrospective follow-up study from the Cutaneous Lymphoma International Consortium. Ann Oncol 2017; 28: 2517-25.

49. Oppmann B, Lesley R, Blom B, et al. Novel p19 protein engages IL-12p40 to form a cytokine, IL-23, with biological activities similar as well as distinct from IL-12. Immunity 2000; 13: $715-25$.

50. Bettelli E, Kuchroo VK. IL-12- and IL-23-induced T helper cell subsets: birds of the same feather flock together. J Exp Med 2005; 201: 169-71.

51. McAleer JP, Kolls JK. Mechanisms controlling Th17 cytokine expression and host defense. J Leukoc Biol 2011; 90: 263-70.

52. Rook $A H$, Kubin $M$, Cassin $M$, et al. IL-12 reverses cytokine and immune abnormalities in Sezary syndrome. J Immunol 1995; 154: 1491-8.

53. Weiner DM, Durgin JS, Wysocka M, et al. The immunopathogenesis and immunotherapy of cutaneous T cell lymphoma: part II, current and future approaches. J Am Acad Dermatol 2021; 84: 597-604.

54. Suchin KR, Cassin M, Gottleib SL, et al. Increased interleukin 5 production in eosinophilic Sézary syndrome: regulation by interferon alfa and interleukin 12. J Am Acad Dermatol 2001; 44: 28-32.

55. Rook AH, Zaki MH, Wysocka M, et al. The role for interleukin-12 therapy of cutaneous T cell lymphoma. Ann N Y Acad Sci 2001; 941; 177-84.

56. Asadullah K, Haeussler A, Sterry W, et al. Interferon $\gamma$ and tumor necrosis factor $\alpha$ mRNA expression in mycosis fungoides progression. Blood 1996; 88: 757-8.

57. Hino R, Shimauchi T, Tokura Y. Treatment with IFN- $\gamma$ increases serum levels of Th1 chemokines and decreases those of Th2 chemokines in patients with mycosis fungoides. J Dermatol Sci 2005; 38: 189-95.

58. Duvic M, Sherman ML, Wood GS, et al. A phase II open-label study of recombinant human interleukin-12 in patients with stage IA, IB, or IIA mycosis fungoides. J Am Acad Dermatol 2006; 55: 807-13.

59. Lemchak DM, Akilov OE. Interleukin-12 immunohistochemistry as a diagnostic tool for patch-stage mycosis fungoides. J Am Acad Dermatol 2016; 75: 1053-4.

60. Doherty SD, Ni X, Doherty CB, et al. Abnormal expression of interleukin-23 in mycosis fungoides/Sézary syndrome lesions. Arch Dermatol Res 2007; 298: 353-6.

61. Daliani D, Ulmer RA, Jackow C, et al. Tumor necrosis factor- $\alpha$ and interferon- $\gamma$, but not HTLV-I tax, are likely factors in the epidermotropism of cutaneous T-cell lymphoma via induction of interferon-inducible protein-10. Leuk Lymphoma 1998; 29: 315-28.

62. Savvateeva MV, Savina MI, Markusheva LI, et al. Relative content of cytokines in different tissues in mycosis fungoides. Bull Exp Biol Med 2002; 134: 175-6.

63. McGirt LY, Thoburn C, Hess A, et al. Predictors of response to extracorporeal photopheresis in advanced mycosis fungoides and Sézary syndrome. Photodermatol Photoimmunol Photomed 2010; 26: 182-91.

64. Hodak E, Akerman L, David M, et al. Cytokine gene polymorphisms in patch-stage mycosis fungoides. Acta Derm Venereol 2005; 85: 109-12.

65. Tracey L, Villuendas R, Dotor AM, et al. Mycosis fungoides shows concurrent deregulation of multiple genes involved in the TNF signaling pathway: an expression profile study. Blood 2003; 102: 1042-50.

66. Izban KF, Ergin M, Qin JZ, et al. Constitutive expression of $N F-\kappa B$ is a characteristic feature of mycosis fungoides: implications for apoptosis resistance and pathogenesis. Hum Pathol 2000; 31: 1482-90.

67. Giri DK, Aggarwal BB. Constitutive activation of NF- $\kappa \mathrm{B}$ causes resistance to apoptosis in human cutaneous $T$ cell lymphoma HuT-78 cells: autocrine role of tumor necrosis factor and reactive oxygen intermediates. J Biol Chem 1998; 273: 14008-14.

68. Tsimberidou AM, Giles FJ, Duvic M, et al. Pilot study of etanercept in patients with relapsed cutaneous T-cell lymphomas. J Am Acad Dermatol 2004; 51: 200-4.

69. Chaudhari U, Romano P, Mulcahy LD, et al. Efficacy and safety of infliximab monotherapy for plaque-type psoriasis: a randomised trial. Lancet 2001; 357: 1842-7.

70. Leonardi CL, Kimball AB, Papp KA, et al. Efficacy and safety of ustekinumab, a human interleukin-12/23 monoclonal antibody, in patients with psoriasis: 76-week results from a randomised, double-blind, placebo-controlled trial (PHOENIX 1). Lancet 2008; 371: 1665-74.

71. Leonardi C, Matheson R, Zachariae C, et al. Anti-interleukin-17 monoclonal antibody ixekizumab in chronic plaque psoriasis. N Engl J Med 2012; 366: 1190-9.

72. Blauvelt A, Reich K, Tsai TF, et al. Secukinumab is superior to ustekinumab in clearing skin of subjects with moderate-tosevere plaque psoriasis up to 1 year: Results from the CLEAR study. J Am Acad Dermatol 2017; 76: 60-9.e9.

73. Langley RG, Elewski BE, Lebwohl M, et al. Secukinumab in plaque psoriasis - results of two phase 3 trials. N Engl J Med 2014; 371: 326-38.

74. Hugh J, Van Voorhees AS, Nijhawan RI, et al. From the Medical Board of the National Psoriasis Foundation. The risk of cardiovascular disease in individuals with psoriasis and the potential impact of current therapies. J Am Acad Dermatol 2014; 70: 168-77.

75. Mattei PL, Corey KC, Kimball AB. Psoriasis Area Severity Index (PASI) and the Dermatology Life Quality Index (DLQI): the correlation between disease severity and psychological burden in patients treated with biological therapies. J Eur Acad Dermatology Venereol 2014; 28: 333-7.

76. Kamstrup MR, Skov L, Zachariae C, et al. Psoriasis and risk of malignant lymphoma: a population-based cohort study. Br J Dermatol 2018; 178: 1435-6.

77. Lee JW, Jung KJ, Kim TG, et al. Risk of malignancy in patients with psoriasis: a 15-year nationwide population-based prospective cohort study in Korea. J Eur Acad Dermatology Venereol 2019; 33: 2296-304

78. Gelfand JM, Shin DB, Neimann AL, et al. The risk of lymphoma in patients with psoriasis. J Invest Dermatol 2006; 126: 2194-201.

79. Biondo G, Cerroni L, Brunasso AMG, et al. Risk of mycosis fungoides in psoriatic patients: a critical review. J Eur Acad Dermatology Venereol 2020; 34: 1186-95.

80. Dequidt L, Franck N, Sanchez-Pena P, et al. Cutaneous lymphomas appearing during treatment with biologics: 44 cases from the French Study Group on Cutaneous Lymphomas and French Pharmacovigilance Database. Br J Dermatol 2019; 181: 616-8.

81. Partarrieu-Mejías F, Díaz-Corpas T, Pérez-Ferriols A, et al. Mycosis fungoides after treatment with tumor necrosis 
factor-alpha inhibitors for psoriasis: progression or onset? Int J Dermatol 2019; 58: e103-5.

82. De A, Raychaudhury T, Rajagopalan M, et al. A case of cutaneous T-cell lymphoma, masquerading as psoriasis, was given etanercept and secukinumab: emphasizing the need for biopsy confirmation before starting biologics. Indian J Dermatol 2017; 62: 533-5.

83. Berthelot C, Cather J, Jones D, et al. Atypical CD8+ cutaneous T-cell lymphoma after immunomodulatory therapy. Clin Lymphoma Myeloma 2006; 6: 329-32.

84. Suga H, Sugaya M, Toyama T, et al. A case of mycosis fungoides with large cell transformation associated with infliximab treatment. Acta Derm Venereol 2014; 94: 233-4.

85. Lafaille P, Bouffard D, Provost N. Exacerbation of undiagnosed mycosis fungoides during treatment with etanercept. Arch Dermatol 2009; 145: 94-5.

86. Martinez-Escala ME, Posligua AL, Wickless H, et al. Progression of undiagnosed cutaneous lymphoma after anti-tumor necrosis factor-alpha therapy. J Am Acad Dermatol 2018; 78: 1068-76.

87. Nikolaou V, Papadavid E, Economidi A, et al. Mycosis fungoides in the era of antitumour necrosis factor- $\alpha$ treatments. Br J Dermatol 2015; 173: 590-3.

88. Foo SH, Shah F, Chaganti S, et al. Unmasking mycosis fungoides/Sézary syndrome from preceding or co-existing benign inflammatory dermatoses requiring systemic therapies: patients frequently present with advanced disease and have an aggressive clinical course. Br J Dermatol 2016; 174: 901-4.

89. Amitay-Laish I, Guenova E, Ortiz-Romero PL, et al. The course of mycosis fungoides under cytokine pathway blockers: a multicentre analysis of real-life clinical data. Acta Derm Venereol 2020; 100: adv00277.

90. Yoo J, Shah F, Velangi S, et al. Secukinumab for treatment of psoriasis: does secukinumab precipitate or promote the presentation of cutaneous T-cell lymphoma? Clin Exp Dermatol 2019; 44: 414-7. 